\title{
Wysokowydajne drążenie elektroerozyjne małych otworów w kompozytach metaliczno-ceramicznych
}

\author{
High-performance Electrical Discharge Machining \\ of small hole in metallic ceramic composites
}

\section{Streszczenie}

W artykule przedstawiono wyniki badań wpływu materiału elektrody roboczej na wysokowydajną obróbkę elektroerozyjną. W badaniach uwzględniono dwa czynniki wejściowe: czas impulsu ton oraz zmianę ciśnienia dielektryka $p$, przy ustalonych pozostałych parametrach obróbki EDM. Obrabiano materiał kompozytowy SIC-Ni o zawartości $20 \%$ węglika krzemu, elektrodami rurkowymi jednokanałowymi i wielokanałowymi wykonanymi z mosiądzu i miedzi. Uzyskano wyniki liczbowe szeregu parametrów charakteryzujących powierzchnię obrobioną, które pozwoliły na sformułowanie wniosków dotyczących obróbki tego materiału.

Słowa kluczowe: drążenie elektroerozyjne; elektrody rurkowe; materiały kompozytowe; struktura geometryczna powierzchni

\begin{abstract}
The paper presents the result of the influence of the working electrode material on high performance Electrical Discharge Machining. In the studies been taken into account two input factors: impulse time $t_{\text {on }}$ and pressure change of the dielectric $p$, at the fixed others parameters of Electrical Discharge Machining. Composite material SiC-Ni with $20 \%$ silicon carbide, single-channel and multi-channel tubular electrodes made of brass and copper were machined. Getting the numerical results of parameters characterizing the machined surface, which allowed us to formulate proposals for the machining of these materials.
\end{abstract}

Keywords: Electrical Discharge Machining; tubular electrodes; composite materials; geometric structure of surface

\section{Wprowadzenie}

W obróbce elektroerozyjnej (EDM) naddatek jest usuwany z przedmiotu obrabianego w wyniku zjawisk towarzyszącym wyładowaniom elektrycznym (wydzielanie ciepła, wzrost temperatury, parowanie, topienie i rozrywanie materiału) w obszarze między przedmiotem obrabianym a elektrodą roboczą. Szczelina międzyelektrodowa wypełniona jest cieczą dielektryczną, której zadaniem jest m.in. usunięcie produktów erozji z przestrzeni międzyelektrodowej. Twardość materiału obrabianego nie wpływa na przebieg procesu, a siły występujące między narzędziem a materiałem są znikome. W związku z tym, obróbka elektroerozyjna jest racjonalną alternatywą przy kształtowaniu elementów wykonanych z materiałów trudno obrabialnych klasycznymi metodami tj.: utwardzona stal, węgliki, stopy o wysokiej wytrzymałości, super twarde materiały przewodzące prąd elektryczny (np. materiały kompozytowe na osnowie metalicznej, ceramika) [1 $\div 3$ ]. Obróbka ta umożliwia także drążenie głębokich otworów, gdzie stosunek średnicy do głębokości jest znacznie mniejszy niż 1:10. Podczas wiercenia elektroerozyjnego elektroda robocza pełni funkcję wiertła, wykonując ruch posuwowy oraz obrotowy. Do mikrowiercenia metodą elektroerozyjną stosowane są elektrody rurkowe (dielektryk jest dostarczany poprzez otwór) [4].

Podczas wiercenia elektroerozyjnego elektrodą w kształcie rurki, zużycie występuje na długości (tzn. następuje skrócenie elektrody) oraz ścianach bocznych $[5,6]$. W wyniku takiego zużycia elektrody roboczej wywiercony otwór ma kształt stożka. Wysokie zużycie elektrody ma wpływ także a stabilność, dokładność oraz wydajność procesu. Możliwość wiercenia głębokich otworów jest ograniczona jedynie przez gromadzenie na dnie otworu produktów obróbki, co powoduje nieprawidłowe wyładowania, szczególnie gdy otwór jest wiercony głęboko. Również powstające podczas procesu pęcherzyki gazowe, blokujące wpłynięcie dielektryka do obszaru obróbki, mogą ograniczać smukłość otworu [7,8]. Jednak w przypadku wiercenia głębokich mikrootworów w metalu, mikrowiercenie elektroerozyjne stanowi jedną z najbardziej efektywnych metod. W przypadku mikroobróbki elektroerozyjnej możliwe jest uzyskanie mikrokształtów z wysoką dokładnością (mniejszą niż $5 \mu \mathrm{m}$ ) i dobrą jakością powierzchni (z chropowatością $R_{a}$ mniejszą niż $\left.0,1 \mu \mathrm{m}\right)$. Wykonane otwory, przy zastosowaniu mikrowiercenia elektroerozyjnego,

Mgr inż. Łukasz Sosinowski; dr hab. inż. Marek Rozenek, prof. PW - Politechnika Warszawska.

Autor korespondencyjny/Corresponding author: lukasz.sosinowski@wp.pl 
mają regularny kształt oraz wysoką dokładność powierzchni bez zadziorów. Jednak parametry obróbki zapewniające powyższe wskaźniki technologiczne, przyczyniają się do niskiej wydajności procesu i znacznego zużycia narzędzia [9].

Do nowoczesnych spiekanych materiałów narzędziowych, o szybko rosnącym znaczeniu w technologii obróbki skrawaniem należą cermetale narzędziowe. Cermetale to materiały kompozytowe spiekane z materiałów ceramicznych i metalowych. Metal jest zwykle spoiwem dla tlenków, borków lub węglików. Używane metale to zwykle nikiel, molibden i kobalt. Cermetale, podobnie jak inne spiekane materiały narzędziowe, np. węgliki spiekane, wytwarzane są metodą metalurgii proszków. Formowanie jest najczęściej przeprowadzane przez jednoosiowe prasowanie, natomiast spiekanie, zależnie od składu chemicznego, przebiega w temperaturze $1400 \div 1550^{\circ} \mathrm{C}$ (z udziałem fazy ciekłej) w piecu próżniowym. W celu polepszenia własności (zmniejszenia porowatości spieku) stosowane jest izostatyczne spiekanie na gorąco HIP (ang. Hot Isostatic Pressing). Dla spiekanych cermetali narzędziowych typową jest struktura rdzeniowo-płaszczowa będąca nośnikiem twardości, powodująca, że cermetale są niewrażliwe na rozrost ziaren podczas spiekania, uzyskując w efekcie drobnoziarnistą strukturę [1].

Struktura geometryczna powierzchni jest jednym z ważniejszych czynników decydujących, o jakości uzyskiwanych wyrobów. Wpływa na własności eksploatacyjne elementów maszyn wyrażone m.in. przez warunki tarcia na powierzchniach stykowych, naprężenia stykowe, wytrzymałość zmęczeniową, odporność na korozję, szczelność połączeń, powierzchniowe promieniowanie cieplne czy własności magnetyczne. Strukturę geometryczną powierzchni (SGP) określa się zbiorem wszystkich nierówności, powstałych w wyniku procesów obróbki i zużycia materiału. Przyjmuje się podział (SGP) na składowe: chropowatość powierzchni, falistość powierzchni i odchyłki kształtu. Podział ten oparty jest na proporcjach wysokości i długości fali nierówności. Pierwsza składowa jest uznawana za jeden z najistotniejszych wyróżników stanu warstwy wierzchniej (WW). Czynnik ten wpływa na przebieg podstawowych zjawisk tribologicznych elemen-

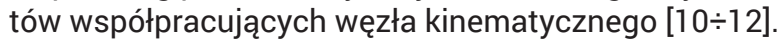

\section{Metodyka badań doświadczalnych}

Do badań wytypowano materiał kompozytowy (SiC-Ni) o zawartości $20 \%$ węglika krzemu. Próbki przed badaniami zostały wyszlifowane, a następnie za pomocą specjalnych uchwytów połączone ze sobą w pakiet. Próby wiercenia elektroerozyjnego wybranego materiału zostały przeprowadzone w Zakładzie Obróbek Wykańczających i Erozyjnych Politechniki Warszawskiej. Wykonano je na drążarce elektroerozyjnej Charmilles Drill 20, widocznej na rysunku 1.

Badania przeprowadzono z użyciem elektrod rurkowych (jedno i wielokanałowych), wykonanych z mosiądzu i miedzi, o średnicy zewnętrznej równej $1 \mathrm{~mm}$. Jako dielektryk zastosowano wodę dejonizowaną, która była dostarczana do obszaru obróbki przez kanały w elektrodzie roboczej (rys. 2).

W badaniach uwzględniono dwa czynniki wejściowe, których wartości były zmienne w następujących przedziałach:

- $t_{\text {on }}$ - czas impulsu $(19 \div 99 \mu \mathrm{s})$,

- $p$ - ciśnienie dielektryka (1\%8 bar).

Przyjęto następujące czynniki wyjściowe:

- liniowe zużycie elektrody roboczej $\left(Z_{e}\right)$,

- czas drążenia $\left(t_{d}\right)$,

- średnica wydrążonych otworów (d),

- chropowatość powierzchni wydrążonych otworów $\left(R_{\mathrm{a}}\right)$.

W celu obliczenia czynników wyjściowych zmierzono: długość elektrody roboczej przed obróbką $\left(h_{p}\right)$ oraz długość

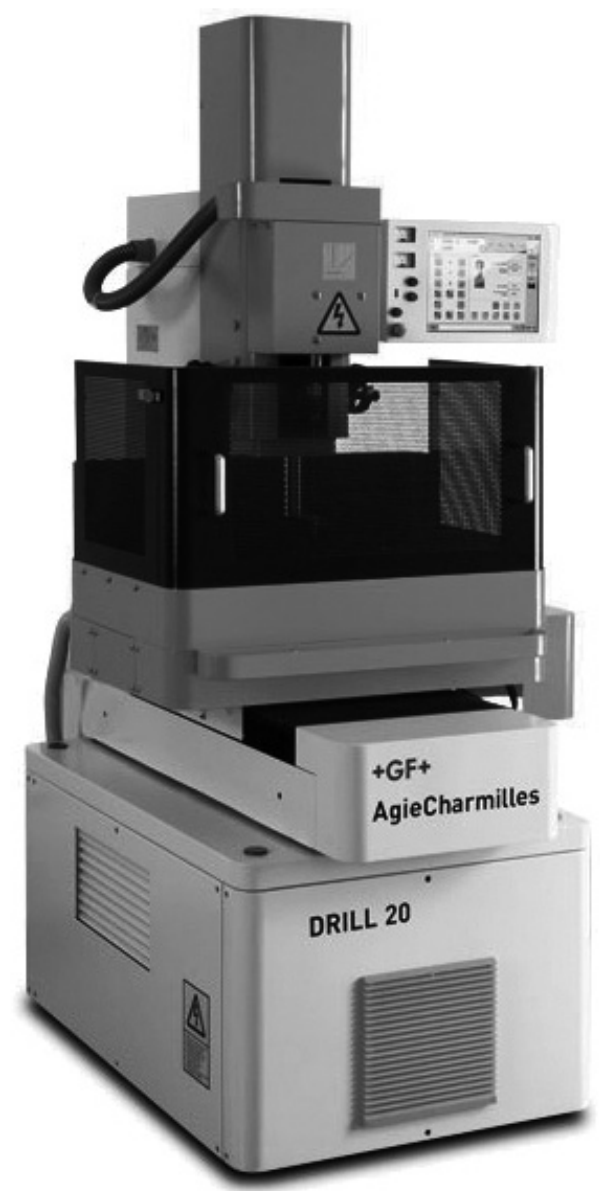

Rys. 1. Drążarka elektroerozyjne Drill 20 firmy Charmilles Fig. 1. Hole drilling EDM Drill 20 - Charmilles Company

elektrody roboczej po obróbce $\left(h_{k}\right)$. Liniowe zużycie elektrody roboczej $\left(Z_{e}\right)$ obliczono wg poniższego wzoru:

$$
\mathrm{Z}_{\mathrm{e}}=\mathrm{h}_{\mathrm{p}}-\mathrm{h}_{\mathrm{k}}
$$

gdzie:

$\mathrm{h}_{\mathrm{p}}$ - długość elektrody roboczej przed obróbką;

$h_{k}$ - długość elektrody roboczej po obróbce.

Natomiast przyjętymi czynnikami stałymi, były:

- materiały obrabiane (materiał kompozytowy WC-Ni o zawartości $20 \%$ WC),

- wysokość materiału obrabianego $\mathrm{h}_{\mathrm{m}}=40 \mathrm{~mm}$,

- elektrody rurkowe przelotowe o średnicach zewnętrznych $\mathrm{d}_{\mathrm{e}}=1 \mathrm{~mm}$ (jedno i wielokanałowe, z mosiądzu i miedzi)

- dielektryk (woda dejonizowana),

- amplituda natężenia prądu I (12 $\div 14 \mathrm{~A})$,

- napięcie wyładowania U $(40 \div 45 \mathrm{~V})$. a)

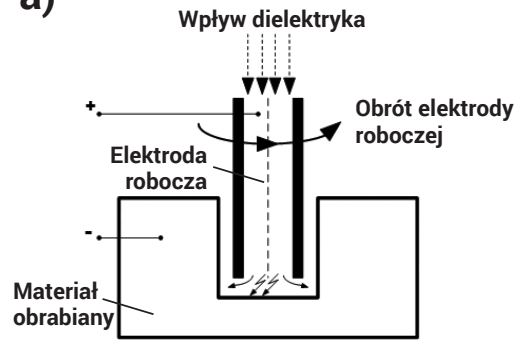

b)

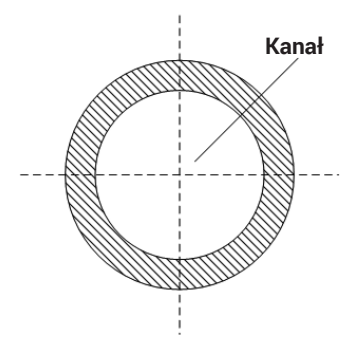

Rys. 2. a) Schemat przedstawiający drążenie elektroerozyjne z dostarczaniem dielektryka poprzez kanał w elektrodzie roboczej, b) przekrój elektrody roboczej jednokanałowej

Fig. 2. a) Diagram showing the electrical discharge machining with dielectric supply through the channel in the working electrode, b) cross-section of the single-channel working electrode 
Tablica I. Parametry obróbki zastosowane w badaniach Table I. The machining parameters used in the study

\begin{tabular}{|c|c|}
\hline \multicolumn{2}{|c|}{ Parametry wejściowe } \\
\hline czas impulsu ton $\mathrm{w}$ przedziale & $19 \div 99 \mu \mathrm{s}$ \\
\hline ciśnienie dielektryka p & $1 \div 8$ bar \\
\hline \multicolumn{2}{|c|}{ Parametry wejściowe ustalone } \\
\hline napięcie wyładowania $U$ & $40 \div 45 \mathrm{~V}$ \\
\hline amplituda natężenia prądu I & $12 \div 14 \mathrm{~A}$ \\
\hline \multicolumn{2}{|c|}{ Parametry wyjściowe } \\
\hline \multicolumn{2}{|l|}{ zużycie elektrody $Z_{\mathrm{e}}$} \\
\hline \multicolumn{2}{|l|}{ czas drążenia $t_{d}$} \\
\hline \multicolumn{2}{|l|}{ średnica wydrążonych otworów d } \\
\hline chropowatość powierzchni $\mathrm{R}_{a}$ & \\
\hline
\end{tabular}

W tablicy I przedstawiono parametry obróbki, z jakimi były realizowane badania.

Pomiary chropowatości oraz średnicy wydrążonych otworów wykonano na profilometrze Talysurf 10.

\section{Analiza wyników}

Analizując wyniki badań wpływu czasu impulsu ton na chropowatość powierzchni (rys. 3), można stwierdzić, że dla wszystkich elektrod roboczych wraz ze wzrostem czasu impulsu $t_{\text {on }}$ wzrasta chropowatość powierzchni. Najkorzystniejsze wyniki osiąga się dla czasów impulsu ton $w$ przedziale od $19 \mu \mathrm{s}$ do $59 \mu$ s. Widać także, że zmiana materiału i kształtu kanału doprowadzającego dielektryk przez elektrodę roboczą wpływa na chropowatość zarówno przy zmianie czasu trwania impulsu $t_{o n}$, jak i zmianie ciśnienia roboczego p. Analizując wykres wpływu ciśnienia roboczego p na chropowatość powierzchni (rys. 4) możemy także zauważyć, iż wraz ze wzrostem ciśnienia chropowatość obrabianej powierzchni maleje.

$\mathrm{Na}$ podstawie analizy wpływu czasu impulsu $t_{\text {on }}$ na średnice drążonego otworu d (rys. 5) można stwierdzić, że dla wszystkich elektrod roboczych wraz ze wzrostem czasu impulsu $t_{\text {on }}$ wzrasta średnica drążonego otworu d. Tak samo jak w poprzednim przypadku, zmiana materiału elektrody ma istotny wpływ na średnice drążonego otworu d, zarówno przy zmianie czasu impulsu $\mathrm{t}_{\mathrm{on}}$, jak i ciśnienia roboczego $\mathrm{p}$. Patrząc na zależność średnicy drążonego otworu d od ciśnienia roboczego $p$ (rys. 6) widać, iż przy wzroście ciśnienia roboczego $\mathrm{p}$ średnice drążonych otworów d maleją.

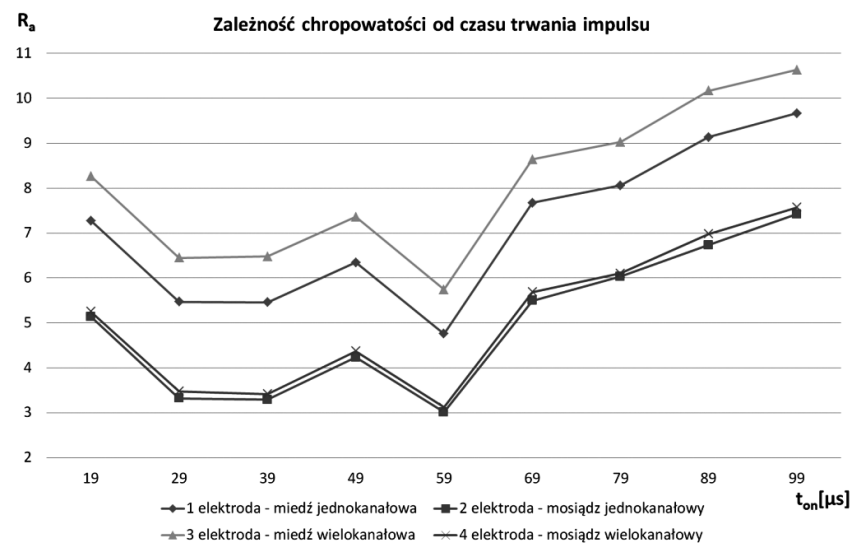

Rys. 3. Zależność parametru chropowatości $R_{a}$ od czasu impulsu ton Fig. 3. Dependence of the surface roughness parameter $R_{a}$ from the impulse time $t_{\text {on }}$

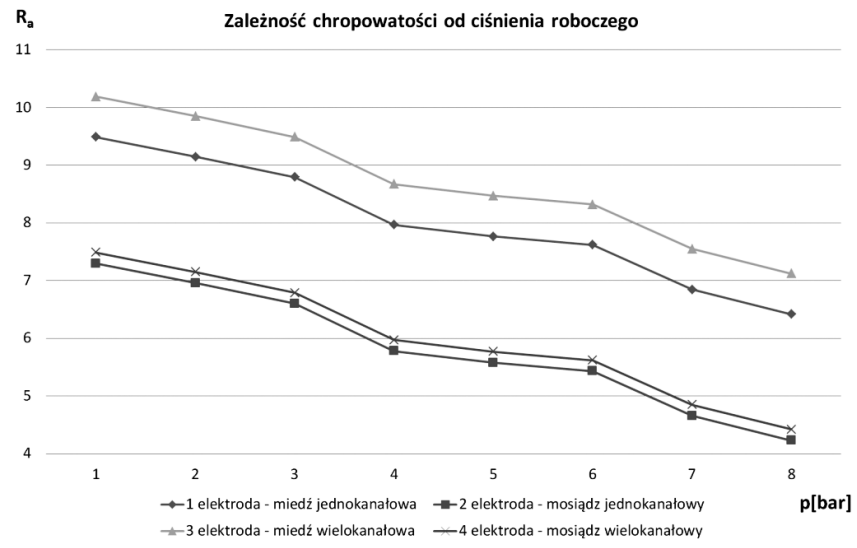

Rys. 4. Zależność parametru chropowatości $\mathrm{R}_{\mathrm{a}}$ od ciśnienia dielektryka $p$

Fig. 4. Dependence of the surface roughness parameter $R_{a}$ from the dielectric pressure $p$

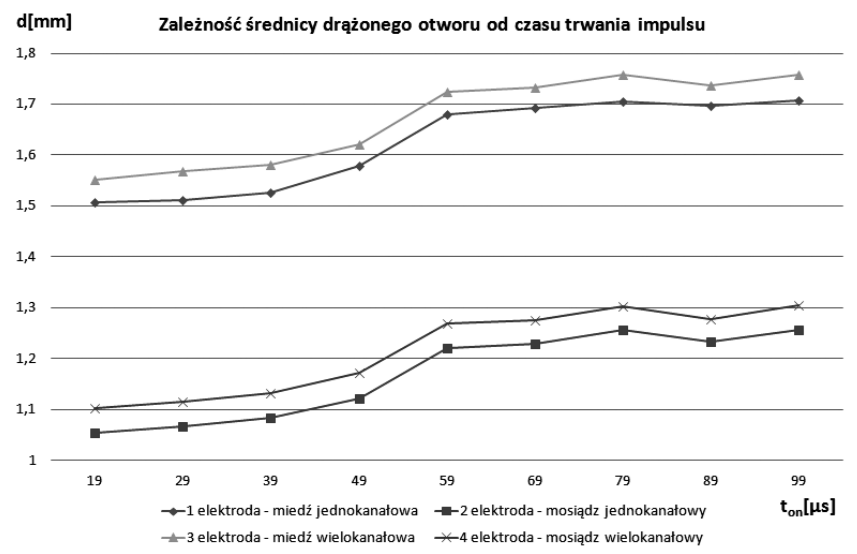

Rys. 5. Zależność średnicy drążonego otworu d [mm] od czasu impulsu $t_{\text {on }}$

Fig. 5. Dependence of the drilling hole diameter $d[\mathrm{~mm}]$ from the impulse time $t_{\text {on }}$

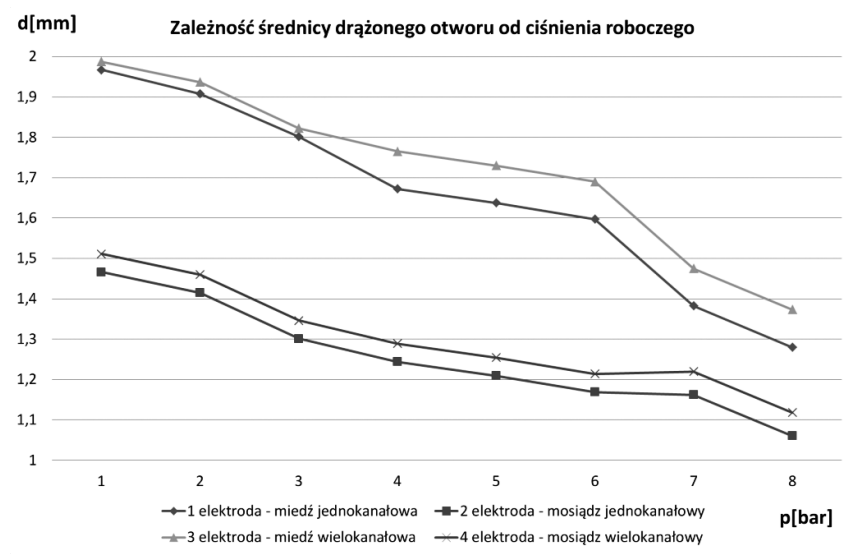

Rys. 6. Zależność średnicy drążonego otworu d [mm] od ciśnienia dielektryka $\mathrm{p}$

Fig. 6. Dependence of the drilling hole diameter $d[\mathrm{~mm}]$ from the dielectric pressure $p$

Obserwując wpływ czasu impulsu $t_{\text {on }}$ na zużycie elektrody $Z_{\text {e }}$ (rys. 7), można zaobserwować, że największy wpływ na zużycie elektrody ma jej rodzaj, natomiast czas impulsu $t_{\text {on }}$ w pewnym stabilnym zakresie od $29 \mu$ s do $89 \mu$ s jest znikomy. Należy jednak zauważyć, że poza tym zakresem następuje gwałtowny wzrost zużycia elektrody $Z_{\mathrm{e}}$. Na podstawie zależności zużycia elektrody $Z_{e}$ od ciśnienia roboczego $p$ (rys. 8) widać, że w przedziale od 1 do 5 barów wraz ze wzrostem ciśnienia roboczego $\mathrm{p}$ wzrasta zużycie elektrody $Z_{\mathrm{e}}$. 


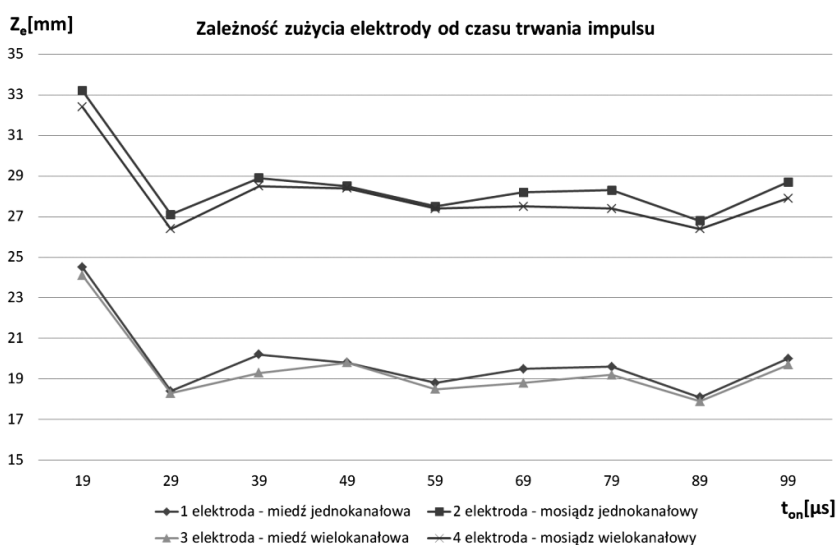

Rys. 7. Zależność zużycia elektrody roboczej $Z_{\mathrm{e}}$ od czasu impulsu ton Fig. 7. Dependence of the working electrode wear $Z_{e}$ from the impulse time $t_{\text {on }}$

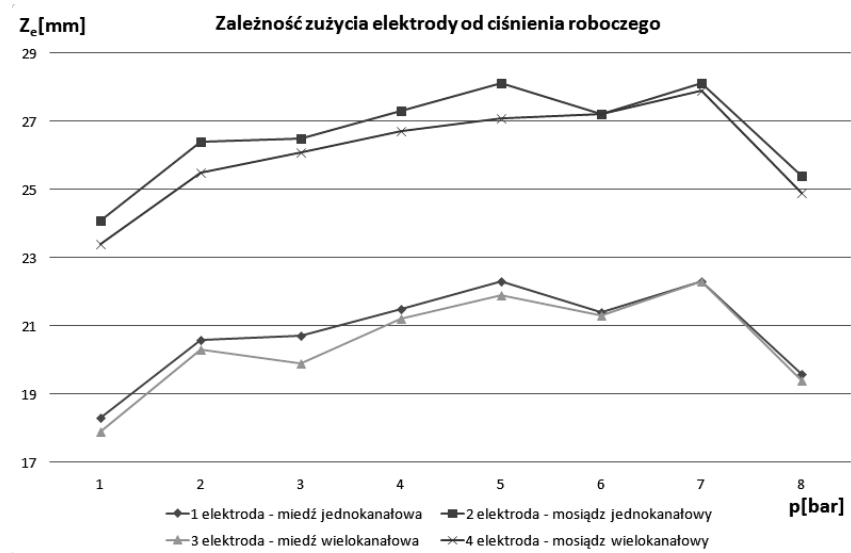

Rys. 8. Zależność zużycia elektrody roboczej $Z_{e}$ od ciśnienia dielektryka $\mathrm{p}$

Fig. 8. Dependence of the working electrode wear $Z_{e}$ from the dielectric pressure $\mathrm{p}$

Analizując wyniki badań wpływu czasu impulsu $t_{\text {on }}$ na czas

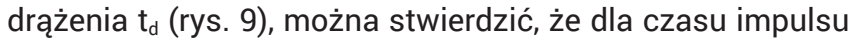
$t_{\text {on }}$ wyższego niż $49 \mu$ s wraz ze wzrostem czasu impulsu $t_{\text {on }}$ skraca się czas drążenia td. Najkorzystniejszy wynik osiąga się dla czasu impulsu ton równego $39 \mu \mathrm{s}$. Patrząc natomiast na zależność czasu drążenia $t_{d}$ od ciśnienia roboczego $p$ (rys. 10), można zauważyć, że najkrótszy czas drążenia $t_{d}$ osiągnięty jest przy ciśnieniu roboczym równym 4 bary.

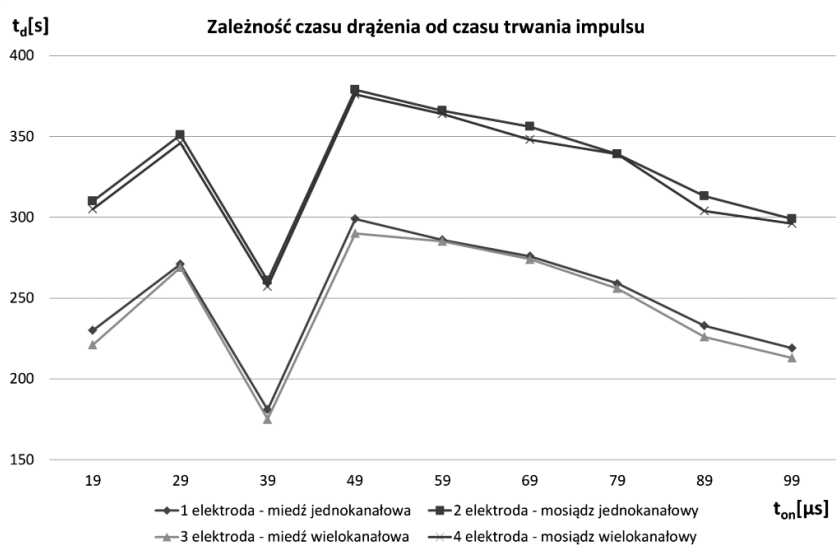

Rys. 9. Zależność czasu drążenia $t_{d}$ od czasu impulsu ton Fig. 9. Dependence of the drilling time $t_{d}$ from the impulse time $t_{\text {on }}$

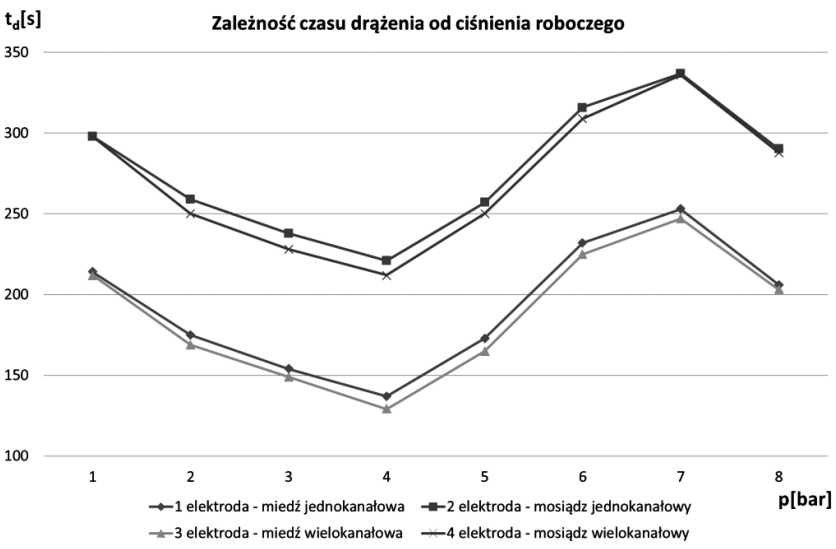

Rys. 10. Zależność czasu drążenia $t_{d}$ od ciśnienia dielektryka $p$ Fig. 10. Dependence of the drilling time $t_{d}$ from the dielectric pressure $\mathrm{p}$

Z uzyskanych wyników badań wynika, że zastosowanie miedzi (w stosunku do mosiądzu), jako materiału na elektrody robocze powoduje wzrost: chropowatości powierzchni obrobionej oraz rozbicia bocznego (średnicy) otrzymywanego otworu. Jednakże zastosowanie miedzi, jako elektrody daje pozytywne skutki obróbki w postaci skrócenia czasu drążenia i zużycia elektrody roboczej.

\section{Podsumowanie}

Na podstawie przeprowadzonych badań wpływu czasu impulsu ton oraz ciśnienia dielektryka p na chropowatość powierzchni, średnicę drążonych otworów d, czas drążenia $t_{d}$ oraz zużycie elektrody $Z_{e}$, można sformułować następujące wnioski:

- wraz ze wzrostem czasu impulsu ton wzrasta chropowatość powierzchni;

- przy wzroście ciśnienia roboczego p chropowatość obrabianej powierzchni maleje;

- gdy wzrasta czas impulsu ton, średnica drążonych otworów d także wzrasta;

- przy wzroście ciśnienia roboczego p średnice drążonych otworów d maleją;

- w pewnym stabilnym zakresie od 29 us do $89 \mu$ s czas impulsu ton nie wpływa na zużycie elektrody $Z_{e}$, natomiast poza tym zakresem zużycie elektrody $Z_{\mathrm{e}}$ gwałtownie wzrasta;

- $\quad$ w przedziale od 1 do 5 bar wraz ze wzrostem ciśnienia roboczego p wzrasta zużycie elektrody $Z_{e}$;

- gdy rośnie czas impulsu $t_{\text {on }}$ to skraca się czas drążenia $t_{d}$;

- kiedy czas przerwy między impulsami $t_{p}$ jest większy bądź równy czasowi impulsu $t_{o n}$, zużycie elektrody $Z_{e}$ gwałtownie wzrasta;

- wraz ze wzrostem czasu przerwy $t_{p}$ wzrasta czas drążenia $t_{d}$;

- zużycie elektrody $Z_{\mathrm{e}}$ rośnie, gdy zwiększa się czas przerwy $t_{\mathrm{p}}$. 


\section{Literatura}

[1] Dobrzański L., Matula G.: Podstawy metalurgii proszków i materiały spiekane, Open Access Library, vol.8 (14), 2012.

[2] Świercz R., Oniszczuk-Świercz D.: Wpływ parametrów obróbki elektroerozyjnej na właściwości użytkowe stali o wysokiej przewodności cieplnej, Mechanik nr 1, s. 29-34, 2015.

[3] Świercz R., Oniszczuk-Świercz D.: Obróbka elektroerozyjna - badanie impulsów elektrycznych napięcia i natężenia prądu, Mechanik nr 2, s. 112 $113,2017$.

[4] El-Hofy H.: Advanced Machining Process. Nontraditional and hybirid machining process, Alexandria University, Egypt, 2005.

[5] Spadło S., Dudek D.: Badania dokładności geometrycznej otworów drążonych metodą EDM, Mechanik nr 12, s. 23-28, 2015.

[6] Spadło S., Dudek D.: Badania wpływu przepłukiwania szczeliny roboczej na efekty obróbki elektroerozyjnej (EDM), Mechanik nr 1, s. 77-79, 2017.

[7] Pham D.T., Ivanov A., Bigot S., Popov K., Dimov S.: An investigation of tube and rod electrode wear in micr EDM drilling, International Journal of Advanced Manufacturing Technology, Volume: 3, Issue: 1-2, pp. 103-109, May 2007.
[8] Jiazhong L., Guoqiang Y., Cong W., Xuejie G., Zuyuan Y.: Prediction of aspect ratio of micro hole drilled by EDM, Journal of Mechanical Science and Technology 27 (1), pp. 185-190, 2013.

[9] Jahan M.P., Rahman M., Wongb Y.S.: A review on the conventional and microelectrodischarge machining of tungsten carbide, International Journal of Machine Tools \& Manufacture 51, pp. 837-858, 2011.

[10] Świercz R., Oniszczuk-Świercz D.: Experimental investigation of surface layer properties of high thermal conductivity tool steel after electrical discharge machining, Metals, vol. 12, 2017.

[11] Piekarski R., Zawora J.: Analiza porównawcza struktur geometrycznych powierzchni (SGP) po procesie kulowania stali 42CrMo4 ze strukturą odniesienia żelaza armco, Przegląd Spawalnictwa vol. 83 (3), s. 32-37, 2016.

[12] Chmielewski T., Golański D.: Modelowanie numeryczne naprężeń własnych w złączach $\mathrm{Al}_{2} \mathrm{O}_{3}-\mathrm{Ti}$ oraz $\mathrm{Al}_{2} \mathrm{O}_{3}-\left(\mathrm{Ti}+\mathrm{Al}_{2} \mathrm{O}_{3}\right)$ formowanych podczas natryskiwania detonacyjnego, Przegląd Spawalnictwa vol. 81, s. 58-62, 2009. 